\title{
An Entropy (Shannon) Based Approach for Determining Importance Weights of Influencing Factors in Selecting Medical Tourism Destinations
}

\author{
Zohreh Dehdashti Shahrokh ${ }^{*}$, Hosnieh Nakhaei Kamalabadi' \\ ${ }^{1}$ Allameh Tabataba'i University, Tehran, Iran
}

Corresponding Author: Zohreh Dehdashti Shahrokh, Ph.D. in Marketing Management, Associate Professor, Allameh Tabataba'l University, Tehran, Iran. Email: zdehdashti33@gmail.com

Received October 26, 2016; Accepted November 6, 2016; Online Published December 5, 2016

\begin{abstract}
Introduction: Medical tourism is currently accepted as a developing industry. It describes the act of leaving home for treatment and care abroad. There are several factors that influence choice of destination for patients in medical tourism. Identification of these factors and prioritization according to importance weights could help international healthcare providers develop their marketing strategy.

Methods: In the first stage of this research, an extensive review was done on recently published studies in medical tourism to identify influential factors on selecting a destination for medical tourism. The review yielded fourteen factors. In the second stage, 40 related papers were selected and the content analysis method was used to calculate frequency of repetition for each factor in the 40 papers. Furthermore, by using the Shannon entropy formula, marginal entropy and importance weight were analyzed for each factor.

Results: Results indicated that the most influential factors on selection of a destination for medical tourism were "quality of care," "cost" and "promotional programs," results that indicate common sense. The least influential factor was "employer encouragement programs," an indication that most medical tourists make a personal choice to embark on medical tourism and employer encouragement programs had lower priority in the decision making process.

Conclusion: This study highlights the most important influential factors on choice of destination among patients, internationally. According to these findings, hospitals providing a service internationally must provide a high quality service at affordable cost. Consideration of travelers' priorities can be applied to develop performance and promotional activities that will attract more patients and increase medical treatment revenue in a country.

Keywords: Medical tourism, Influential factors, Importance weights, Destination selection, Shannon entropy
\end{abstract}

Citation: Dehdashti Shahrokh Z, Nakhaei Kamalabadi H. An entropy (Shannon) based approach for determining importance weights of influencing factors in selecting medical tourism destinations. Int J Travel Med Glob Health. 2016;4(4):115-121. doi:10.21859/ijtmgh-040406.

\section{Introduction}

Today, a reverse shift has occurred in medical tourism. Patients from advanced economies now leave their homes in search of medical treatment to a destination that will provide high quality medical care at an affordable price, especially in Asian countries. ${ }^{1}$ This industry has shown significant growth in the past decade; India, Singapore, and Thailand have emerged as favorable destinations for medical treatment among patients from all around the world. ${ }^{2}$

The growth of medical tourism is due to several factors such as high costs of medical treatment ${ }^{3,4}$; lack of sufficient insurance coverage for certain treatments ${ }^{5}$; long waiting queues for certain procedures ${ }^{6,7}$; unavailability of specific treatments in a patient's home country due to legal or cultural reasons; lack of trust in the quality of a local treatment ${ }^{8}$ and access to technology, expertise, and overall better healthcare services in foreign countries.,

The purpose of this study was to identify the influential factors on selection of a medical tourism destination and to prioritize them. The research question was as follows; what are the most important factors in selecting medical tourism destinations? The originality of this study was identification of 14 influential factors through an extensive review of the related literature. Then the content analysis method was used to calculate the repeated frequency of each factor in 40 of the most recently published papers (published between 2007 to 2016). Finally, the marginal Shannon entropy and importance weights for these 14 factors were calculated and analyzed. The results of this research could be applied to help foreign healthcare providers to consider patients' priorities in making 
selections for medical tourism destinations and to develop better programs through reducing weaknesses and increasing strengths to attract more international patients.

\section{Influential Factors in Medical Tourism}

Based on the purpose of this study, 14 influential factors were identified from the latest published studies, these factors were: economic condition, political condition, medical tourism infrastructure, tourism attractions, marketing \& promotional activities, cultural factors, distance, cost, international accreditation, quality, physician training, facilitators, building brands (partnership) and employer encouragement. A brief explanation of these 14 factors has been overviewed in the following.

Economic conditions: “The country's economic conditions impact the availability of medical goods and services." ${ }^{10}$ Countries with a stable economy could attract more medical tourists through an ability for quick responses to stimuli and provision of good quality services for patients. ${ }^{11}$

Political conditions: "Low corruption and a good rule of law" are signs of political stability which influence the attractiveness of a destination for medical tourism. ${ }^{12}$ Recently, terrorist threats and political insurgence have increased attention among medical tourists to the political situation in a destination country. Hospitality and travel safety were significant priorities for international patients. Therefore they usually chose destinations with no risk of revolution or uprising. ${ }^{11}$

Medical tourism infrastructure: "Medical tourism is a combination of medical services and the tourism industry." In the healthcare industry, the healthcare system of a destination country is an important factor. Rather than covering 'medical tourists proper' and their companions, importance of a country's tourism and healthcare infrastructure is due to the patient's attention to medical skills and facilities in selecting a destination for medical tourism. ${ }^{13}$ This has brought about increased attention in developing countries to provision of higher quality healthcare services to international patients through provision of better equipped healthcare centers. ${ }^{14}$

Tourism attraction: Medical tourists can take advantage of enjoying their trip during the treatment period by choosing a destinations with exotic tourist attractions. ${ }^{15}$ Today the strategy of marketing campaigns that promote "medical tourism" is to combine health care services with other activities such as adventure, relaxation, and fun. ${ }^{10}$

Promotions: Previously, only some hospitals and destinations were promoted as medical tourism providers, but "today there are hundreds of hospitals and clinics and over thirty different countries promoting it." 16 Even the governments of some medical tourism countries such as South Africa, India, Malaysia, Philippines, and Singapore have promotional programs in their "national tourism marketing campaigns" to market themselves as "global health destinations." 17,18

Cultural factors: "Cultural similarity" and "language similarity" are significant factors in selecting a medical destination. ${ }^{3,19}$ Medical tourists usually travel to countries with language similarity, or countries that have a similar culture and where English is spoken. ${ }^{20}$ Muslims usually travel to destinations with a similar culture and Malaysia has become a favorite destination for patients from Indonesia and the Gulf. ${ }^{3}$ Religious differences could also lead to medical tourism. The Sunni and Shi'a branches of Islam have different rules about fertility treatments. Therefore for Shia Muslims living in Sunni Islamic country, Iran (a majority Shi'a Muslim country) has become a favorable destination for receiving reproductive treatment. ${ }^{15}$

Distance: Distance or "proximity to place of residency" has been identified as a driver for medical tourism. ${ }^{21}$ Geography influences a medical traveler's choice of destination since a great part of medical tourism occurs across a relatively short distance. ${ }^{20}$ For example, most of the "Mexican diaspora" living in the United States travel south, since cultural familiarity makes communication easier and besides, they can visit friends and families. ${ }^{22-24}$

Costs: Generally, patients choose medical tourism because of the high cost of treatment in their home country. The aim of an American patient when traveling abroad for medical treatment is to receive high cost and high risk treatment at lower cost using the advantage of much larger cost savings. ${ }^{24}$ Medical costs are much cheaper in medical tourism destinations than in the United States, for instance a heart bypass that costs about US $\$ 133000$ in United States will cost around $\$ 7000$ in India. India is offering treatments at lower prices that other places in the world, which is a cost advantage for attracting more medical tourists. ${ }^{18}$

International accreditation: international accreditation is used for testing the quality, skills and surgery records of international clinics and hospitals. ${ }^{24}$ Therefore medical centers accredited by international institutes such as the US JCI body (Joint Commission International-an arm of the body that accredits most US hospitals in an attempt to improve safety and quality of care) or International Organization for Standardization (ISO) promote themselves as providing a high level of quality medical care services. ${ }^{25}$

Quality of care: The main goal of patients traveling from high income countries to developing countries is to receive high quality medical care at a cheaper price. ${ }^{26}$ Quality in the medical sector includes both quality of the facility (international accreditation, ${ }^{13}$ hospital brand ${ }^{17}$ and advanced technological equipment ${ }^{27}$ ) and the care quality provided by the medical staff (doctors and nurses). ${ }^{28}$

Physicians' training: Academic credentials are used to market physicians' skills and expertise. International healthcare providers use degrees, fellowships at elite institutions, and US board certifications to promote their physicians' expertise. Actually, they are conveying the message that physicians with "international" degrees are providing an "elite-level" healthcare service. ${ }^{5}$

Facilitators: Facilitators play an important role in marketing healthcare services and influencing patients' choices in selecting a destination for medical treatment. ${ }^{29}$ They try to find appropriate and reliable medical centers for patients, offering them assurances of quality and safety, planning the pre and post travel arrangements such as flights, accommodation, transportation, translators, visiting tourism attractions and after care treatment. ${ }^{24,25}$

Building brands (partnership): today, medical tourism destinations promote themselves as a partner of "brandedname academic institutions." This partnership occurs in establishing branch campuses and awarding local students 
with prestigious degrees. ${ }^{5,25}$ The partnership of the National University of Singapore with Duke University for establishing a medical school in Singapore and the partnership of Harvard Medical International with Dubai Healthcare City for providing postgraduate programs for training medical professionals are good examples in this. ${ }^{5}$

Employer encouragement: "Go for heavy hitters. One whale is worth a million goldfish." ${ }^{30}$ Due to inefficient marketing of low cost healthcare services to individual patients in medical tourism, the new strategy of US medical brokerages was to promote procedures for targeting small and large companies along with individual customers. ${ }^{31}$ Using this strategy, employers (for example the Blue Ridge Paper Products Inc. case) and insurance companies offered bonuses and cash incentives to their employees (e.g. employees' airfares and extra sick leave in addition to a US\$10 000) if they chose to be treated at an Indian approved hospital. ${ }^{32}$

\section{Methods}

This research was conducted as a qualitative study based on the method of content analysis for gathering data from the latest published papers (2016). The researchers conducted a comprehensive and systematic review of published academic studies in the field of medical tourism to answer the question: what are the most important factors for patients selecting a destination for medical tourism? The review was accomplished in four steps: (1) identification of the relevant literature (88 published papers and reports and 12 published dissertations were studied); (2) identification of 14 influential factors in selecting medical tourism destination by reviewing the relevant literature using a checklist; (3) selection of the 40 most recent papers according to two constraints; papers written in English and publication date between the years 2007 and 2016; and (4) counting the repeated frequency of each factor in selected papers and finally calculating the marginal entropy and importance weight for each factor using Microsoft Excel software.

The selected influential factors included cost, quality of care, promotion, economic condition, political condition, distance, medical tourism infrastructure, international accreditation, physician training, facilitators, building brands and employer encouragement. By studying these papers accurately, the frequency of repeated times each factor had in the article were counted (shown in Table 1) and then Shannon entropy was used to calculate marginal entropy and then weight of each factor.

The entropy concept, introduced by Shannon (1948), measures the uncertainty of a random variable in the information theory. The expected value of the information contained in a message is quantified using this concept. ${ }^{59}$ Shannon entropy uses a mathematical function for explaining the expected value of alternative conditions of a variable. The entropy function always has a positive value. "Because of the many attributes, the entropy concept is accepted as an objective criterion that can be used in measuring information content of any statistical process." Marginal entropy is defined as below:

$$
H(\mathrm{X})=-\mathrm{K}\left[\sum_{i=1}^{m} P\left(x_{i}\right)\left(L N P\left(x_{i}\right)\right]\right.
$$

\section{$K=\frac{1}{L N(N)}$}

where

$x_{i}$ is a discrete random variable,

$\mathrm{K}$ is a constant unit used in entropy calculation, where $\mathrm{k}=0.271$ in this study.

$\mathrm{N}$ is the number of basic events that has $P\left(x_{i}\right)$ probabilities, which it is 40 reviewed papers. ${ }^{60,61}$

Importance weight ${ }^{61}: W_{j}=\frac{H(x)_{j}}{\sum_{j=1}^{n} H(x)_{j}}$

\section{Results}

Table 1 shows frequency of repetitions for each of the 14 influential factors in the 40 studied papers. By calculating importance weights and marginal entropy for these 14 influential factors (results shown in Table 2), indications showed that quality, cost and marketing and promotional activities were the most important influential factors in selecting a destination in medical tourism. As seen in Table 2 , although most researchers considered cost as the primary factor for embarking on medical tourism, the results of marginal entropy combined with importance weights showed that quality was the most important issue for medical tourists and cost (with a little difference) was the second most important factor. This result makes sense since the aim of international patients travelling for medical treatment is to increase their health status, so they seek destinations with a high quality service at the best available price. Actually these two factors are considered together with higher quality as the top priority.

However, marketing and promotional programs were considered as the third most important factor to influence client choice. And furthermore, promotional programs provided by health centers and governments could make medical tourism more attractive for a country. But employer encouragement programs were determined as the least important factor. It might mean that most medical tourists are engaging in medical tourism personally and employer encouragement programs have a less significant role in the decision making process. In other words, medical tourism seems to be a more self-selected decision than an employer encouraged decision.

\section{Discussion}

The medical tourism industry is a new financial resource for a country's medical system. ${ }^{43}$ Thus it is essential for government policy makers to know which influential factors affect patients' choice of destination. Understanding and prioritizing these influential factors could help managers to develop and market their healthcare services and related strategic planning. The findings of this study could prioritize 14 influential factors for destination selection by including importance weights (Figure 1). Based on the related studies on tourist perception and motivation for medical tourism, these 14 identified influential factors significantly influenced the medical tourist's choice of destination. Results indicate that the three most important influential factors were quality, cost and marketing activities.

The results of this study correlate with some earlier findings of similar studies. ${ }^{10,26}$ This study has reemphasized 
Table 1. The Frequency of Each Influencing Factor in Reviewed Papers

\begin{tabular}{|c|c|c|c|c|c|c|c|c|c|c|c|c|c|c|}
\hline \multirow[b]{2}{*}{ Articles } & \multicolumn{14}{|c|}{ Variables } \\
\hline & 尺) & 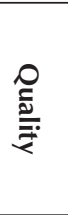 & 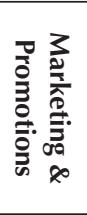 & 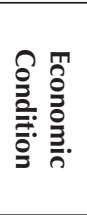 & 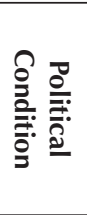 & 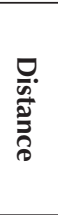 & 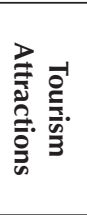 & 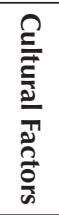 & 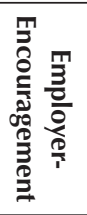 & 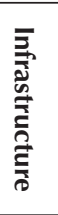 & 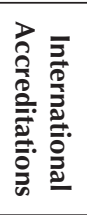 & 芳. & 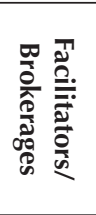 & 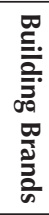 \\
\hline A-Lamki ${ }^{8}$ & 5 & 5 & 1 & 0 & 3 & 0 & 0 & 0 & 0 & 0 & 0 & 0 & 0 & 0 \\
\hline Altin et $\mathrm{al}^{33}$ & 2 & 0 & 3 & 2 & 0 & 0 & 0 & 1 & 0 & 0 & 0 & 0 & 0 & 0 \\
\hline Amouzgar et $\mathrm{al}^{34}$ & 4 & 5 & 9 & 6 & 5 & 1 & 1 & 0 & 0 & 4 & 2 & 0 & 0 & 0 \\
\hline Anvekar ${ }^{35}$ & 12 & 11 & 13 & 1 & 1 & 0 & 1 & 2 & 0 & 3 & 6 & 2 & 0 & 20 \\
\hline $\begin{array}{l}\text { Arunanondchai and } \\
\text { Fink }^{36}\end{array}$ & 7 & 10 & 2 & 18 & 0 & 0 & 0 & 1 & 0 & 0 & 0 & 0 & 0 & 0 \\
\hline Asadi et $\mathrm{al}^{37}$ & 8 & 10 & 7 & 10 & 3 & 0 & 7 & 7 & 0 & 5 & 0 & 0 & 0 & 0 \\
\hline Azadi et al ${ }^{9}$ & 3 & 44 & 0 & 1 & 0 & 0 & 0 & 1 & 0 & 2 & 4 & 5 & 1 & 0 \\
\hline Bies and Zakharia ${ }^{6}$ & 53 & 14 & 0 & 5 & 4 & 0 & 0 & 0 & 19 & 3 & 1 & 1 & 0 & 0 \\
\hline Bustamante $^{38}$ & 5 & 3 & 2 & 15 & 0 & 0 & 0 & 2 & 0 & 0 & 0 & 0 & 0 & 0 \\
\hline Carruth and Carruth ${ }^{39}$ & 43 & 17 & 0 & 3 & 0 & 1 & 0 & 0 & 4 & 0 & 0 & 0 & 2 & 0 \\
\hline Cohen $^{40}$ & 16 & 8 & 0 & 4 & 2 & 3 & 0 & 1 & 1 & 0 & 5 & 2 & 8 & 0 \\
\hline Connell ${ }^{3}$ & 26 & 13 & 15 & 9 & 3 & 9 & 0 & 24 & 0 & 7 & 5 & 0 & 1 & 1 \\
\hline Crooks et $\mathrm{al}^{41}$ & 20 & 8 & 4 & 0 & 2 & 2 & 0 & 1 & 2 & 0 & 0 & 0 & 16 & 0 \\
\hline Crooks et $\mathrm{al}^{2}$ & 44 & 21 & 55 & 3 & 0 & 3 & 0 & 0 & 0 & 0 & 0 & 0 & 10 & 1 \\
\hline Delgoshaei et $\mathrm{al}^{42}$ & 14 & 14 & 3 & 0 & 0 & 0 & 2 & 0 & 0 & 1 & 9 & 0 & 0 & 0 \\
\hline $\begin{array}{l}\text { Fetscherin and } \\
\text { Stephano }^{28}\end{array}$ & 27 & 23 & 9 & 5 & 4 & 3 & 21 & 9 & 0 & 5 & 4 & 21 & 0 & 2 \\
\hline Gan and Feredrick ${ }^{25}$ & 31 & 29 & 0 & 0 & 2 & 0 & 0 & 2 & 10 & 0 & 16 & 3 & 15 & 2 \\
\hline Gholami et $\mathrm{al}^{43}$ & 4 & 47 & 0 & 0 & 0 & 0 & 0 & 2 & 0 & 0 & 0 & 0 & 0 & 0 \\
\hline Hadi $^{44}$ & 70 & 35 & 7 & 8 & 5 & 0 & 1 & 0 & 0 & 9 & 4 & 0 & 4 & 1 \\
\hline Hanefeld et $\mathrm{al}^{45}$ & 36 & 0 & 3 & 1 & 0 & 0 & 0 & 0 & 0 & 0 & 0 & 0 & 0 & 0 \\
\hline Hazarika $^{46}$ & 10 & 14 & 0 & 0 & 0 & 0 & 0 & 0 & 0 & 4 & 3 & 0 & 0 & 0 \\
\hline Helble $^{47}$ & 10 & 8 & 0 & 0 & 0 & 1 & 0 & 1 & 0 & 0 & 1 & 2 & 0 & 0 \\
\hline Heung et al ${ }^{17}$ & 28 & 15 & 37 & 6 & 1 & 1 & 10 & 1 & 0 & 12 & 11 & 3 & 0 & 7 \\
\hline $\begin{array}{l}\text { Horowitz and } \\
\text { Rosenweig }\end{array}$ & 7 & 4 & 0 & 4 & 1 & 0 & 0 & 0 & 0 & 0 & 0 & 0 & 0 & 0 \\
\hline Izadi et al ${ }^{49}$ & 13 & 7 & 1 & 2 & 0 & 0 & 4 & 9 & 0 & 5 & 0 & 2 & 0 & 0 \\
\hline Jabbari et al ${ }^{50}$ & 5 & 8 & 12 & 0 & 0 & 0 & 6 & 0 & 0 & 1 & 0 & 2 & 0 & 0 \\
\hline Johnston et $\mathrm{al}^{51}$ & 15 & 3 & 1 & 0 & 0 & 1 & 0 & 0 & 0 & 9 & 7 & 2 & 7 & 0 \\
\hline Kumar and $\mathrm{Raj}^{1}$ & 19 & 10 & 1 & 1 & 0 & 0 & 1 & 0 & 0 & 1 & 9 & 0 & 0 & 0 \\
\hline Lunt et $\mathrm{al}^{52}$ & 15 & 17 & 10 & 0 & 0 & 2 & 0 & 5 & 0 & 0 & 4 & 0 & 3 & 1 \\
\hline Lunt and Mannion ${ }^{53}$ & 5 & 1 & 5 & 5 & 4 & 0 & 0 & 0 & 0 & 0 & 1 & 0 & 0 & 0 \\
\hline Manouchehri et al ${ }^{54}$ & 16 & 13 & 18 & 6 & 5 & 1 & 2 & 5 & 0 & 4 & 3 & 2 & 0 & 7 \\
\hline Mohamad et $\mathrm{al}^{55}$ & 1 & 2 & 0 & 5 & 1 & 0 & 0 & 2 & 0 & 0 & 1 & 0 & 34 & 0 \\
\hline $\begin{array}{l}\text { Moghimehfar and } \\
\text { Nasresfahani }^{15}\end{array}$ & 4 & 3 & 0 & 0 & 1 & 4 & 4 & 1 & 0 & 0 & 0 & 0 & 0 & 0 \\
\hline Ormond $^{56}$ & 6 & 10 & 17 & 8 & 8 & 0 & 0 & 0 & 0 & 2 & 1 & 0 & 1 & 1 \\
\hline Runnels \& Carrera ${ }^{57}$ & 5 & 16 & 0 & 0 & 0 & 0 & 0 & 0 & 0 & 0 & 10 & 0 & 3 & 0 \\
\hline Sarwar et $\mathrm{al}^{4}$ & 20 & 29 & 10 & 1 & 0 & 0 & 0 & 0 & 0 & 0 & 0 & 0 & 0 & 0 \\
\hline Saleh et $\mathrm{al}^{58}$ & 6 & 5 & 34 & 0 & 0 & 1 & 0 & 5 & 0 & 0 & 7 & 0 & 0 & 0 \\
\hline Smith et $\mathrm{al}^{12}$ & 21 & 16 & 0 & 1 & 0 & 0 & 0 & 0 & 0 & 0 & 11 & 0 & 0 & 0 \\
\hline Turner ${ }^{5}$ & 37 & 29 & 26 & 3 & 0 & 0 & 5 & 0 & 2 & 1 & 12 & 5 & 22 & 11 \\
\hline Yu and $\mathrm{Ko}^{13}$ & 61 & 7 & 6 & 0 & 0 & 0 & 1 & 0 & 1 & 1 & 1 & 0 & 1 & 1 \\
\hline Sum & 738 & 534 & 311 & 133 & 54 & 33 & 66 & 80 & 39 & 79 & 138 & 52 & 128 & 55 \\
\hline
\end{tabular}


Table 2. The Calculated Importance Weight and the Marginal Entropy of the Influencing Factors

\begin{tabular}{lcc}
\hline Variables & $\boldsymbol{W}_{\boldsymbol{j}}$ & $\boldsymbol{H}(\boldsymbol{X})$ \\
\hline Quality of care & 0.0985 & 0.9180 \\
Cost & 0.0974 & 0.9083 \\
Marketing \& promotion & 0.0821 & 0.7657 \\
Economic condition & 0.0796 & 0.7738 \\
International accreditation & 0.0792 & 0.7379 \\
Medical tourism infrastructure & 0.0725 & 0.6762 \\
Political condition & 0.0716 & 0.6673 \\
Cultural factors & 0.0673 & 0.6279 \\
Distance & 0.0656 & 0.6112 \\
Facilitators & 0.0644 & 0.5999 \\
Physician training & 0.0614 & 0.5778 \\
\hline Tourism attraction & 0.0598 & 0.5578 \\
Building brands & 0.0555 & 0.5165 \\
Employer encouragement & 0.0413 & 0.3890 \\
\hline
\end{tabular}

that quality was the most important factor for customers in the medical tourism industry. The McKinsey \& Company study reported results similar to those of this research. Their findings indicated that the most important influential factors on patient choice of destination were quality drivers such as advanced technology, better quality of care, quicker access and cost of treatment came next. "When selecting a destination, such patients generally traded off perceived quality against other factors such as cost, distance and unfamiliar cultures." ${ }^{27}$ Cost was neither the only driver nor the first priority for embarking on medical tourism. ${ }^{24}$ Understanding patient's priorities, Indian healthcare institutions strategy was to benefit from high quality medical services which was followed by cost advantage. ${ }^{18}$

Marketing and promotional activities took the third place in patient's priorities. These activities, by governments, medical centers and facilitators increased patients' trust in a healthcare-providing destination. Consideration of the economic condition of the destination country was the fourth most important factor. Economic instability of a destination country led to loss of medical tourists as Iran lost its market share to other regional competitors due to economic instability; ongoing changes in medical cost, frequently fluctuating currency exchange rates and high inflation rates of previous years. ${ }^{54}$ Patients considered international accreditation as the fifth priority. This factor brings quality assurance to clients. Medical tourism infrastructure had the sixth place in priority ranking. In choosing medical destination, tourism and healthcare infrastructures were significant factors. ${ }^{13}$ The seventh priority was political condition. Safety and security assurance was considered an important issue while traveling abroad, therefore countries with stable political climate are favorable medical tourism destinations. ${ }^{11}$ Cultural factors and distance were ranked as eighth and ninth priorities, respectively for medical tourists. Medical travelers generally travelled to closer destinations in neighboring countries that benefitted from cultural and language compatibility. ${ }^{3}$ Findings indicate that facilitators influenced patient choice of destination as the 10th priority. Although facilitators can arrange more favorable and easier travel for clients, some patients chose a destination because of a suggestion made by friends or relatives, also through browsing a hospital website. Physician degrees and even partnership with branded name healthcare institutes could be 11th and 13rd priority for medical tourists. Since the findings of this study were based upon content analysis of selected papers, it can be concluded that not all authors in the study appointed these two factors. These factors could have had higher priority ranking in a survey type research. Although medical tourists preferred to choose destinations with tourist attractions, this factor came after many other important factors such as quality, cost, economic and political situation and even cultural compatibility, in 12th place, which made sense. Findings indicate that employer-encouragement programs gained the last place among influential factors and this was confirmed by some other research concluding that "self-selected medical tourism" was more preferable than a program encouraged by an employer. ${ }^{6}$ Most medical tourists

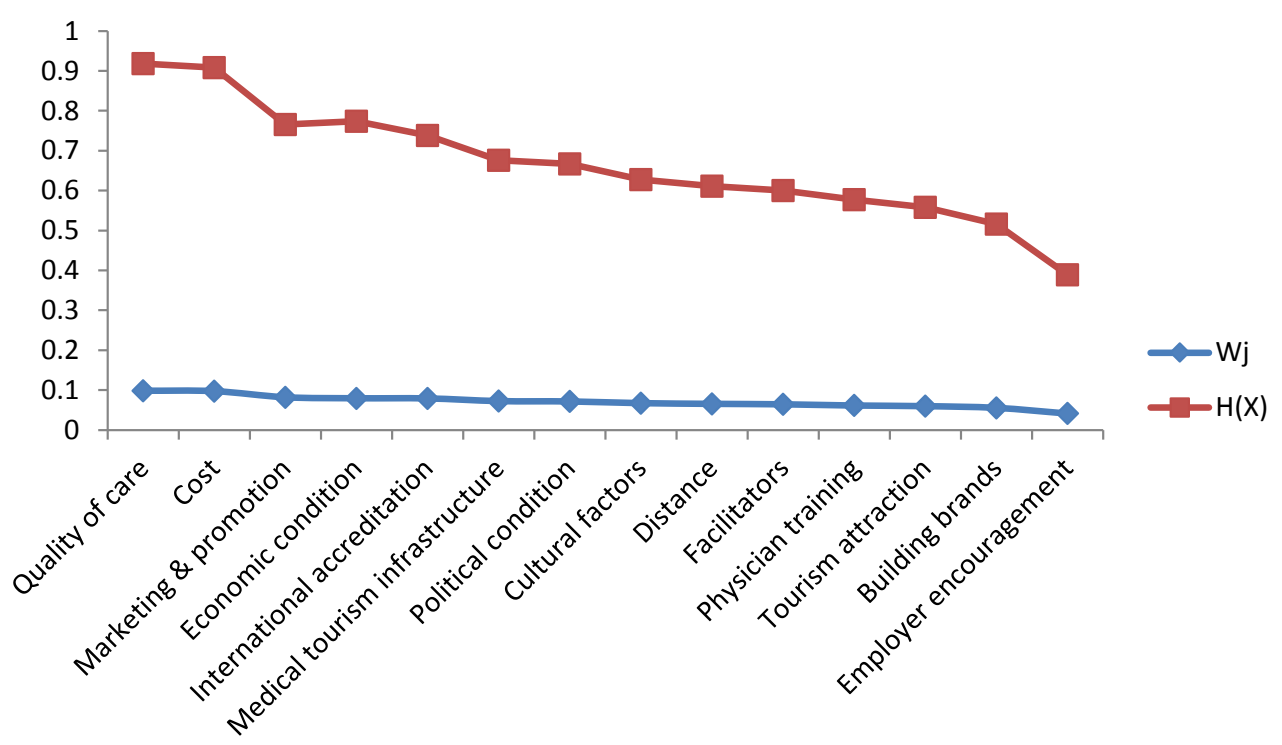

Figure 1. Importance Weight and the Marginal Entropy of the Influencing Factors. 
decided to get into medical tourism personally and employer encouragement programs had the least impact on the decision making process.

Results of this study ranked influential factors according to importance weights as discussed above. It must be noted that this ranking was the result of a content analysis study and some of these factors could gain a higher rank in a surveyconducted research. However, the first three priorities and the last priority correlated with the findings of similar studies.

\section{Conclusion}

The findings of this study suggest that in a growing healthcare industry, hospitals that promote medical tourism should emphasize quality, lower cost, promotional activities, economic situation, international accreditation, and medical infrastructure. For attracting more medical tourism, healthcare providers must consider the priorities of international patients and try to exceed their quality needs. Since cost was determined as the second most important factor, it can be concluded that international patients were eager to receive higher quality healthcare services at the best available price. Promotional programs were also attractive to medical tourists. Considering the priorities of medical tourist, international healthcare providers could improve their level of performance and develop their marketing strategy to attract more medical tourists. Although quality and cost were the most important priorities for patients, there were other factors that influenced the decision-making process of medical tourists in selecting a destination for medical treatment. Factors such as choosing a destination that is economically and politically stable, high medical tourism infrastructure and cultural similarity should be considered by governments of medical destinations in policy making and promotional programs.

\section{Authors' Contributions}

All authors contributed equally in the preparation of this paper.

\section{Conflict of Interest Disclosures}

None declared.

\section{Ethical Approval}

The data presented in this study is the result of the authors' research in this area and they confirm that they were not published previously.

\section{Funding/Support}

This research was supported by the Allameh Tabataba'i University, Tehran, Iran.

\section{Acknowledgments}

This paper has been extracted from a $\mathrm{PhD}$ dissertation.

\section{References}

1. Kumar GS, Raj RK. Status, growth and impact of medical tourism in India. Int J Pharm Sci Rev Res. 2015;34(1):284-291.

2. Crooks VA, Turner L, Snyder J, Johnston R, Kingsbury P. Promoting medical tourism to India: Messages, images, and the marketing of international patient travel. Soc Sci Med. 2011;72(5):726-732.

\section{Research Highlights}

\section{What Is Already Known?}

Medical tourism is a fast growing industry. Patients decide to get into medical tourism for various reasons such as the high cost of treatment and a lack of access to necessary treatment or low quality healthcare services in their home country. There are some factors that influence a patient's decision in selecting a destination for medical treatment.

\section{What This Study Adds?}

The number of influential factors used in this study and their ranking according to importance weights distinguishes it from other studies. The findings indicate that rather than quality and cost, which are the most important factors, other factors such as economic and political stability and medical tourism infrastructure were ranked highly in patient's priority in choice of destination and should therefore be considered by policy makers in countries promoting health tourism.

\section{doi:10.1016/j.socscimed.2010.}

3. Connell J. Contemporary medical tourism: conceptualization, culture and commodification. Tour Manag. 2013;34(1-13).

4. Sarwar AAM, Noorhazilah AM, Azura O. Medical tourist's perception in selecting their destination: a global perspective. Iran J Public Health. 2012;41(8):1-7.

5. Turner L. Medical Tourism and the global marketplace in health services: U.S. patients, international hospitals, and the search for affordable health care. Int J Health Serv. 2010;40(3):443-467.

6. Bies W, Zacharia L. Medical tourism: outsourcing surgery. Math Comput Model. 2007;46:1144-1159.

7. Helble M. The movement of patients across borders: Challenges and opportunities for public health. Bull World Health Organ. 2011;89(1):68-72. doi:10.2471/BLT.10.076612.

8. Al-Lamki L. Medical tourism: beneficence or maleficence. Sultan Qaboos Univ Med J. 2011;11(4):444-447.

9. Azadi F, Maleki M, Tabibi SJ, Azmal M. A medical tourist perception of iranian hospital quality: limited employee foreign language skills negatively impact communication. Int J Hosp Res. 2012;2:85-90.

10. Connell J. Medical tourism: Sea, sun, sand and...surgery. Tour Manag. 2006;27:1093-1100.

11. Smith PC, Forgione DA. Global utsourcing of healthcare: a medical tourism decision model. Journal of Information Technology Case and Application Research. 2007;9(3):19-30. doi:10.1080/152280 53.2007.10856117.

12. Smith R, Martinez-Alvarez M, Chanda R. Medical tourism: a review of the literature and analysis of a role for bi-lateral trade. Health Policy. 2011;103(2):276-282. doi:10.1016/j. healthpol.2011.06.009.

13. Yu JY, Ko TG. A Cross-cultural study of perceptions of medical tourism among Chinese, Japenese and Korean tourists in Korea. Tour Manag. 2012;33:80-88.

14. Deliotte Center for Health Solutions. Medical Tourism: Consumers in search of value. Deloitte Consulting LLP; 2008:1-30.

15. Moghimehfar F, Nasr-Esfahani MH. Decisive factors in medical tourism destination choice: a case study of Isfahan, Iran and fertility treatments. Tour Manag. 2011;32(6):1431-1434. doi:10.1016/j. tourman.2011.01.005.

16. Saadatnia F, Mehregan MR. Determining and prioritizing factors affecting to increase customers attraction of medical tourism from the perspective of Arabic countries. Int J Mark Stud. 2014;6(3):155. doi:10.5539/ijms.v6n3p155.

17. Heung VCS, Kucukusta D, Song D. Medical tourism development in Hong Kong: An assessment of the barriers. Tour Manag. 2011;32:995-1005. doi:10.1016/j.tourman.2010.08.012. 
18. Kaur M. Medical Tourism in India. Indian J Res. 2014;3(1):64-66.

19. Medical tourism climate survey 2013. Medical Tourism Association; 2013.

20. Ye BH, Yuen PP, Qiu HZ, Zhang VH. Motivation of medical tourists: an exploratory case study of Hong Kong medical tourists. in a PTA annual conference. Bangkok, Thailand; 2008.

21. Alleman BW, Lugur T, Reisinger HS, Martin R, Horowitz MD, Cram P. Medical tourism services available to residents of the United States. J Gen Intern Med. 2011;26(5):492-497. doi:10.1007/ s11606-010-1582-8.

22. Inhorn M. Diasporic dreaming: return reproductive tourism to the Middle East. Reproductive Medicine Online. 2011;23:582-591. doi:10.1016/j.rbmo.2011.08.006.

23. Laugesen MJ, Vargas-Bustamante A. A patient mobility framework that travels: European and United States-Mexican comparisons. Health Policy. 2010;97:225-231. doi:10.1016/j. healthpol.2010.05.006.

24. Lunt N, Smith RD, Mannion R, et al. Implications for the NHS of inward and outward medical tourism: a policy and economic analysis using literature review and mixed-methods approaches. Health Serv Deliv Res. 2014;2(2):262. doi:10.3310/hsdr02020.

25. Gan LL, Ferederick JR. Medical tourism facilitators: patterns of service differentiation. Journal of Vacation Marketing. 2011;17(3):165-183. doi:10.1177/1356766711409181.

26. Bookman MZ, Bookman KR. Medical Tourism in Developing Countries. New York, NY: Palgrave Macmillan; 2007.

27. Ehrebeck T, Guevara C, Mango PD, Cordina R, Singhal S. Health care and the consumer. McKinsey Quarterly. 2008;4:80-91.

28. Fetscherin M, Stepahno M. The medical tourism index: Scale development and validation. Tour Manag. 2016;52:539-556.

29. Stephano R-M. Medical Tourism Facilitators: The Good, the Bad-the Unknown. Medical Tourism Association; 2013-2014.

30. Leone FH. Marketing Healthcare Services to Employers. Sea Hill Press, Inc; 2012.

31. Foster M, Mason M. Businesssses may move healthcare overseas. Washingtonpost. Novermber 2, 2006. http://www.washingtonpost. com/wp-dyn/content/article/2006/11/02/AR2006110200728. html.

32. Milestine A, Smith M. America's new refugees - seeking affordable surgery offshore. N Engl J Med. 2006;355(16):1637-1640. doi:10.1056/nejmp068190.

33. Altin U, Bektas G, Antep Z, et al. The international patient's portfolio and marketing of turkish health tourism. Procedia Soc Behav Sci. 2012;58:1004-1007. doi:10.1016/j.sbspro.2012.09.1080.

34. Amouzagar S, Mojaradi Z, Izanloo A, Beikzadeh S, Milani M. Qualitative examination of health tourism and its challenges. Int J Travel Med Glob Health. 2016;4(3):88-91. doi:10.21859/ ijtmgh-040304.

35. Anvekar SR. Medical tourism in India: a strategic approach towards effective branding for health care services marketing. Am J Manag. 2012;12(2/3):108-116.

36. Arunanondchai J, Fink C. Globlization for health: Trade in health services in the ASEAN region. Health Promot Int. 2007;21(S1):5966.

37. Asadi R, Daryaei M. Strategies for development of Iran health tourism. Eur J Soc Sci. 2011;23(3):329-344.

38. Bustamante AV. Globalization and medical tourism: the North American experience. Int J Health Policy Manag. 2014;3(1):47-49. doi:10.1080/02508281.2010.11081639.

39. Carruth PJ, Carruth AK. The financial and cost accounting implications of medical tourism. Int Bus Econ Res J. 2010;9(8):135140 .

40. Cohen E. Medical travel- A critical assessment. Tourism Recreation Research. 2010;35(3):225-237. doi:10.1080/02508281.2010.110 81639.

41. Crooks VA, Kingsbury P, Snyder J, Johnston R. What is known about the patient's experience of medical tourism? A scoping review. Health Serv Res. 2010;10:266-278. doi:10.1186/14726963-10-266.
42. Delgoshaei B, Ravaghi H, Abolhassani N. Importance-performance analysis of medical tourism in iran from medical tourists and medical services provider's perspective: 2011. Middle-East Journal of Scientific Research. 2012;12(11):1541-1547.

43. Gholami M, Jabbari A, Kavosi Z, Gholami M. Service quality in iran's medical tourism: hospitals in Shiraz city. Int J Travel Med Glob Health. 2016;4(1):19-24. doi:10.20286/ijtmgh-040119.

44. Hadi A. Globlization, medical tourism and health equity. Symposium on Implications of Medical Tourism for Canadian Health and Health Policy. Symposium on Implications of Medical Tourism for Canadian Health and Health Policy; Ottawa, Canada; November 13, 2009.

45. Hanefeld J, Horsfall D, Lunt N, Smith R. Medical tourism: a cost or benegit to the NHS? PLoS One. 2013;8(10):e70406. doi:10.1371/ journal.pone.0070406.

46. Hazarika I. Medical tourism: its potential impact on the health workforce and health systems in India. Health Policy Plann. 2009;25:248-251

47. Helble M. The movement of patients across borders: challenges and opportunities for public health. Bull World Health Organ. 2011;89:68-72. doi:10.2471/blt.10.076612.

48. Horowitz MD, Rosenweig JA, Jones CA. Medical tourism: Globalization of the healthcare marketplace. MedGenMed. 2007;9(4):33.

49. Izadi M, Ayoobian A, Nasiri T, Joneidi N, Fazel M, Hosseinpourfard MJ. Situation of health tourism in Iran opportunity or threat. J Mil Med. 2012;14(2):69-75.

50. Jabbari A, Zarchi MKR, Kavosi Z, Shafaghat T, Keshtkaran A. The marketing mix and development of medical tourism in Shiraz. Mat Soc Med. 2013;25(1):32-36. doi:10.5455/msm.2013.25.32-36.

51. Johnston R, Crooks VA, Snyder J, Kingsbury P. What is known about the effects of medical tourism in destination and departure countries? A scoping review. Int J Equity Health. 2010;9:24. doi:10.1186/1475-9276-9-24.

52. Lunt N, Mannion R, Exworthy M. A framework for exploring the policy implications of UK medical tourism and international patients flow. Soc Policy Adm. 2013;47(1):1-25. doi:10.1111/ j.1467-9515.2011.00833.x.

53. Lunt N, Mannion R. Patient mobility in the global marketplace: a multidisciplinary perspective. Int J Health Policy Manag. 2014;2(4):155-157. doi:10.15171/ijhpm.2014.47.

54. Manouchehri J, Farhangi AA, Someeh S, Shakibaei E. The challenges of Kish health tourism: a case study. Int J Basic Appl Sci. 2014;3(3):335-343. doi:10.14419/ijbas.v3i3.3133.

55. Mohamad WN, Omar A, Haron MS. The moderating effect of medical travel facilitators in medical tourism. Procedia Soc Behav Sci. 2012;65:358-363. doi:10.1016/j.sbspro.2012.11.134.

56. Ormond M. Shifting subjects of health-care: Placing 'medical tourism' in the context of Malaysian domestic healthcare reform. Asia Pac Viewp. 2011;52(3):247-259. doi:10.1111/j.14678373.2011.01457.x.

57. Runnels V, Carrera PM. Why do patients engage in medical tourism? Maturitas. 2012;73:300-304. doi:10.1016/j. maturitas.2012.08.011.

58. Saleh SA, Hussain F, Saud MBB, Isa MA. Strategy marketing \& competitve analysis of Malaysian medical tourism industry. International Journal of Business, Economics and Law. 2015;6(2):39-47.

59. Liu X-Y, Li R-L, Zhao H-W, et al. Quality assessment of speckle patterns for digital image correlation by Shannon entropy. Optik - International Journal for Light and Electron Optics. 2015;126(23):4206-4211. doi:10.1016/j.ijleo.2015.08.034.

60. Murat YS. An entropy (Shannon) based traffic Safety Level Determination approach for block spots. Procedia Soc Behav Sci. 2011;20:786-795. doi:10.1016/j.sbspro.2011.08.087.

61. Danaeifard H, Alvani SM, Azar A. Qualitative Research Methodology in Management: A Comprehensive Approach. Tehran: Saffar; 2004. [Persian]. 